\title{
A Bibliometric Study for Articles of the Jordanian Journal of Libraries and Information (1965-2017)
}

\author{
Afaf A. Abu Sirhan', Serhan A. Al tawalbeh, Ibrahim N. Mohsen and Mohammad A. Al Mahameed \\ 1 Library and Information Science, Al Hussein Bin Talal University, Maan/ Jordan; satwlbh@yahoo.com \\ (S.A.A); ibahem_mohsen@yahoo.com (I.N.M.); mahameed@ahu.edu.jo (M.A.A.M.) \\ *Corresponding author: afaf@ahu.edu.jo; TEL.: 00962775639744
}

\begin{abstract}
This study provides the bibliographical analysis of the articles produced by various authors from the year 1965 to 2017. Bibliometric approach is used to analyze data that is provided through standard statistical calculations. Findings indicated that, the highest rate of researches were produced during 1980s, with the average publication of 28.6 articles each year. Findings further indicated that the ratio of male population was high in producing articles, where most of the articles were based on single authorship. The analysis of the trend in terms of article type indicated researchers high level interest in producing biographies during 90s, which was then shifted to the production of articles related to library management after the beginning of 2000. Following the findings of this study, it is suggested to encourage researchers to explore diverse topics that lacked the interest of different authors.
\end{abstract}

Keywords: Jordanian, Bibliometric, Libraries and Information, Intellectual, Articles, Publications.

\section{Introduction}

The current era is known as the "age of education and knowledge", since the advancement of knowledge resulted in the technological, industrial and economic development. Education produces ideas and serves as the main source in competing nations, by generating the national income and the development of different economic resources Resnik [1]. Information producing nations and societies are focused on generating useful information, and strives to identify the gaps in knowledge, while filling them through continuous research and development. Information centered countries have also been directing their societies, centers of research and academic beacons to research and produce information according to their needs, to solve problems and increase productivity based on the updated information that has become one of the most important inputs for production [2].

Journals and periodicals play a critical role in this regard, and serve as an important source of knowledge for researchers as they are distinguished by the modernity of their information particularly in any field of study [3]. This specifically emphasizes on the value of bibliometric studies that have a significant role in libraries and information and is associated to the counting of publications, citations, analysis of co-citations and patents citation [4].

The term Bibliometrics first appeared in 1969 through a research published by Pritchard titled as "Statistical Bibliography and Bibliometrics", and was defined as, "Mathematical and statistical applications of book measurements and other means of communication" [5]. The bibliometric method gives the direction to researchers and help them in the selection of a research topic [6]. It is further defined as an approach that relies on standard and quantitative criteria by using statistical and mathematical methods of publishing studies on books, writings, literature, intellectual production or publishing in general, documentary communication, written communication, and bibliographies [7]. 
According to the Online Dictionary for Library and Information Science (ODLIS), "bibliometric refers to the use of mathematical and statistical methods to study and define patterns of use of materials and services within the library or to analyze the historical development of a specific set of literature, especially its authoring, publication and use. Before the mid-twentieth century, the quantitative study of bibliographic data and use was known as the "bibliography Statistic" [8]. However, due to its widespread contribution, the bibliometric method has become one of the most used methods in the field of libraries and information, as it has evolved in providing information of the relationship between various authors and their contribution of work through analyzing citations [9].

Bibliometric based on bibliographic control for intellectual production works as an important scientific reference in library and information studies to determine the intellectual, temporal and spatial trends of production in knowledge and its associated characteristics [10]. The bibliometric measurements are further important as they study the intellectual product, through the developed literature after its issuance. These studies are analyzed and interpreted due to its importance in measuring the volume of intellectual output in various subject sectors as it depends on different quantitative and qualitative statistical methods to analyze the intellectual output.

Contributions of the Jordanian Journal of Libraries and Information are important, as they began to issue different papers from 1965 until now, which made Jordan first country to have library of science since 1960s [11]. However, to analyze its literary contributions, an accumulative cumulative analytic index was prepared to assess its overall publications from the beginning of the journal until 2012. An index was also prepared for all issues of the Jordanian journal for Libraries and Information between 2013 to 2017, exhibiting important details which includes title of the researches, author names, and keywords which serves as the descriptors for researchers and scholars to obtain the required researches in the science of libraries and information. Since periodicals, references and book lists enrich the libraries [12], therefore indexing them is one of the most important library services provided by the Jordanian Library and Information Association.

Following the significance of the periodicals published in the Jordanian Journal of Library and Information Sciences, this study aims to analyze the production in the Jordanian Journal of Library and Information Sciences during the period between 1967 and 2017, based on the bibliometric methodology of analyzing intellectual production. Studies that have been published in the last five decades were included, due to the researchers' need to identify the gaps found in the objective knowledge that should be focused on to encourage publishing of various researches in the necessary thematic and applied knowledge.

The importance of this study stems from the fact that it is based on the analysis of the Jordanian Journal of Libraries and Information, which is a specialized journal issued by the Jordanian Library and Information Association. Contributions of this study are significant as it serves as the important source of information for researchers in the field of library and information science. Due to the scarcity of the bibliometric studies, this study serves as the first study conducted in Jordan. The information provided in this study will guide the researcher in the identification of strengths and weaknesses present in the existing research work produced. It would further serve as a source of guide and direction for future publications. Considering the aim of this study, the present study intends to answer the following questions:

1. How many researches have been published in Jordanian journal of libraries and information sciences in years from 1965 to 2017 ?

2. What is the ratio of male and female authors in contributing articles in Jordanian Journals of libraries and Information sciences?

3. How many researches were published with individual authorship?

4. How many researches were published with co-authorship?

5. Which type of articles have been explored in the timeframe of 1965 to 2017 ? 


\section{Literature Review}

Several bibliometric studies have conducted in to analyze the trends of publications in different journals. Naheem [13] conducted a study and outlined the bibliographical characteristics of the Journal, Library Progress (International) of India. The study was specifically centered to the research articles published during the period of 2010-2015. Findings of the study highlighted that $53.4 \%$ articles consisted of two authors only, whereas, $41 \%$ of the remaining were produced by single authors. The average rate of productivity of each authority was identified up to 0.54 . Maximum productivity of research articles was held through Indian scholars during the given time duration.

Bakri and Willett [14] on the other hand focused on the Malaysian Journal of Library and Information Sciences (MJLIS) and conducted a bibliographical study from year 2001 to 2006. Findings of the present study were compared with those provided in the bibliographical study of Tiew et al. [15], who particularly focused on the period of 1996-2000. The comparative analysis of the studies indicated that the number of publications in the given journal has significantly increased from 75 articles mentioned in the study of Tiew et al. [15] to 85 articles presented in the study of Bakri. Also, statistically significant changes were recorded in terms of article type, number of references, and in the length of articles. The results concluded that 87 citations attracted about 161 articles out of which 52 were self-cited whereas, $14 \%$ articles were those that were at least once cited from MJLIS.

The numerical and the tropical trends for the production of deposited Jordanian books were studied by Suleiman [12]. The aim of this study was to identify the number of Jordanian books submitted in the National library of Jordan between the duration of 2002 to 2011, along with the quality of production. However, the overall analysis revealed no significant correlation between the quantity and size of production and chronology. Besides, the annual rate of production of Jordan books were 1106.2 books, where the dominating language among those books were Arabic with highest numbers of 10563 (95.49\%) books published. The study further recommended a need to publish books on topics which have not been studied in previous years.

A similar study was conducted by Gore et al. [16], who analyzed the trends in research activity in the Journal of Health Sciences Librarianship. Bulletin of the Medical Library Association and Journal of the Medical Library Association was used as a source to identify the published articles between 1991 to 2007. A comparative analysis between the given study and a previous study which covered the period of 1966 to 1990 was conducted. Bibliometric and content analysis of the studies were undertaken, to identify the subject, analytical techniques used in the studies, number of citations, number of authors, first author affiliations etc. Findings indicated that a significant progress has been made in the past few years in the health sciences librarianship research. Finally, a gap in the use of improved research methodologies, usage of applied vs theoretical studies was identified.

Another bibliometric study was conducted by Huang and Chang [17], to analyze the use of interdisciplinary approach from studies published between 1978-2007. Three methods of bibliometric analyses were used that includes, co- authorship, direct citation and bibliographic coupling. Findings of the study identified Library and Information Sciences (LIS) as the most preferable cited source in the studies of information sciences researches. The above review of the studies indicates the existing gap in studies, since none of the researcher has focused on conducting a bibliographical study on the Jordanian Journal of Libraries and Information.

\section{Methods}

\subsection{Study Design}

This study identifies and regulates the researches published in the Jordanian Journal of Libraries and Information through bibliometric study analysis. Only articles, books and 
topics that were published in the year from 1965 to 2017 in Jordanian journal of library and information were included in this study.

\subsection{Study Sample}

All the articles that were published in the Jordanian Journal of libraries and information were selected as the study sample. The selection was based on statistical data, according to the time factor which was represented in the number of researches published with respect to year, gender, type of authorship and the type of articles published during the following periods: 1965-1969, 1970-1979, 1980-1989, 1990-1999, 2000-2009 and 20102017.

\subsection{Formatting of Mathematical Components}

The data was collected by preparing an index through web data collection which helped the researchers to reach to the desired result conveniently. The research tool included the web data base where collected data were combined in a single cumulative index.

Keywords such as, Jordanian, library, information, bibliometric study, bibliographical study, Jordan, were searched on google and google scholar to retrieve data related to the articles published in the Jordanian journal. Time limit was also set from the year to 1965 to 2017 and only articles that lay in this timeframe were included. To analyze the articles published in Jordanian journals, bibliometric study was divided according to the criteria that include: Analysis of authors including their names, affiliations and gender, forms of information resources such as, books, periodicals research, websites, etc., and concept of studies which include the topics and thematic areas.

\subsection{Inclusion and Exclusion Criteria}

The conference journals and journals index were excluded from the subjects of this research study. The articles that were published in Jordanian Journals of Libraries and Information were only included in this research, whereas, articles published in any other journal were excluded. Articles that were published in years from 1965 to 2017 only in Jordanian Journal of Libraries and information were included.

\section{Results and Discussion}

Table 1 of this study shows findings related to the number of studies published in each period between 1965 to 2017. Findings indicated that the highest and the lowest number of studies were published during the 1960s, with the overall publications of $n=39$ and $\mathrm{n}=10$ respectively. Following this i.e., during the year 1970s, a fluctuation in the number of articles has been observed where the highest number of articles were $n=32$, while minimum number of articles were $\mathrm{n}=16$. 
Table 1. Number of research papers published for each year from 1965 to 2017.

\begin{tabular}{|c|c|c|c|c|c|c|c|c|c|c|c|}
\hline $\begin{array}{l}\text { Years } \\
\text { of } 60 \mathrm{~s}\end{array}$ & $\begin{array}{c}\text { No. of } \\
\text { articles }\end{array}$ & $\begin{array}{l}\text { Years } \\
\text { of } 70 \mathrm{~s}\end{array}$ & $\begin{array}{l}\text { No. of } \\
\text { articles }\end{array}$ & $\begin{array}{l}\text { Years } \\
\text { of } 80 \mathrm{~s}\end{array}$ & $\begin{array}{l}\text { No. of } \\
\text { articles }\end{array}$ & $\begin{array}{l}\text { Years } \\
\text { of } 90 \mathrm{~s}\end{array}$ & $\begin{array}{l}\text { No. of } \\
\text { articles }\end{array}$ & $\begin{array}{c}\text { Years } \\
\text { of } \\
2000 \mathrm{~s}\end{array}$ & $\begin{array}{c}\text { No. of } \\
\text { articles }\end{array}$ & $\begin{array}{c}\text { Years of } \\
2010-2017\end{array}$ & $\begin{array}{c}\text { No. of } \\
\text { articles }\end{array}$ \\
\hline- & - & 1970 & 30 & 1980 & 34 & 1990 & 26 & 2000 & 25 & 2010 & 21 \\
\hline- & - & 1971 & 32 & 1981 & 26 & 1991 & 33 & 2001 & 14 & 2011 & 22 \\
\hline- & - & 1972 & 32 & 1982 & 31 & 1992 & 32 & 2002 & 17 & 2012 & 19 \\
\hline- & - & 1973 & 32 & 1983 & 27 & 1993 & 24 & 2003 & 17 & 2013 & 22 \\
\hline- & - & 1974 & 31 & 1984 & 34 & 1994 & 24 & 2004 & 19 & 2014 & 21 \\
\hline 1965 & 10 & 1975 & 32 & 1985 & 46 & 1995 & 28 & 2005 & 21 & 2015 & 19 \\
\hline 1966 & 34 & 1976 & 21 & 1986 & 21 & 1996 & 29 & 2006 & 14 & 2016 & 19 \\
\hline 1967 & 35 & 1977 & 30 & 1987 & 29 & 1997 & 22 & 2007 & 23 & 2017 & 16 \\
\hline 1968 & 19 & 1978 & 16 & 1988 & 25 & 1998 & 18 & 2008 & 7 & - & - \\
\hline 1969 & 39 & 1979 & 17 & 1989 & 13 & 1999 & 23 & 2009 & 11 & - & - \\
\hline Total & 137 & & 273 & & 286 & & 259 & & 168 & & 159 \\
\hline $\begin{array}{l}\text { Aver- } \\
\text { age }\end{array}$ & 27.4 & & 27.3 & & 28.6 & & 25.9 & & 16.8 & & 19.875 \\
\hline
\end{tabular}

In the 1980s, a remarkable growth in the number of articles submitted to the journal was observed, while making the record of $n=46$ articles. The year of 1990s then faced a considerable reduction of articles in comparison to the previous years, as the highest number of published articles were $n=33$, which declined in 1998 with a submission of $n=18$ articles only. The years between 2000-2017 faced a serious flux, since the average number of studies published during 2000-2009 and 2010-2017 were n=16.8 and n=19.8.

As for the average number of researches, the largest average was in the period 19801989 with accumulated average of $(28.6 \%)$, and the lowest average was in the 2000 decade with average percentage of $(16.8 \%)$. Finally, for all the other decades the overall average of the published articles was close to the average of decade 2000.

Table 2 illustrate the findings for the gender wise ratio of authorship, with and without organization. Among all the periods, the percentage of male authorship was the highest with (66.7\%) from year 1965 to 1969 and lowest male authorship was observed between 1990 to 1999 with $(38.0 \%)$, then that of females with the highest authorship in years from 2010 to 2017 with percentage of (41.6\%) and lowest authorship was in years from 1970 to 1979 with the accumulated percentage of $(10.2 \%)$.

Table 2. Male and female authorship ratio, with and without organizational Authorship.

\begin{tabular}{ccccccc}
\hline & \multicolumn{7}{c}{ Periods } \\
\cline { 2 - 7 } Types & $\mathbf{1 9 6 5 -}$ & $\mathbf{1 9 7 0 -}$ & $\mathbf{1 9 8 0 -}$ & $\mathbf{1 9 9 0 -}$ & $\mathbf{2 0 0 0 -}$ & $\mathbf{2 0 1 0 -}$ \\
& $\mathbf{1 9 6 9}$ & $\mathbf{1 9 7 9}$ & $\mathbf{1 9 8 9}$ & $\mathbf{1 9 9 9}$ & $\mathbf{2 0 0 9}$ & $\mathbf{2 0 1 7}$ \\
\cline { 2 - 7 } Male & $\%$ & $\%$ & $\%$ & $\%$ & $\%$ & $\%$ \\
Female & 66.7 & 63.6 & 56.4 & 38.0 & 47.8 & 58.4 \\
With Organization & 24.4 & 10.2 & 22.6 & 22.3 & 29.2 & 41.6 \\
(author) & 2.2 & 2.3 & 0.8 & 3.8 & 1.8 & 0 \\
Without Author & 6.7 & 18.2 & 10.5 & 18.5 & 6.6 & 0 \\
\hline
\end{tabular}

In addition, the ratio of publications with the organization authorship was highest in the year from 1970-1979 with (2.3\%) of publications and the lowest was in years from 19801989 with $(0.3 \%)$ publications, whereas, no publications were occurred in year from 20102017. The rate of authorship with organization and without authorship publications ratio was in years from 2010 to 2017 there were no publications whereas, in years from 1970 to 1979 was the highest without author publications with (18.2\%). 
According to the table 3, individual authorship is the most common, as the percentage of research with individual authorship in these periods is greater with accumulation of (100\%) in 1965 to 1969 . Co-authorship on the other hand was identified as least common in comparison to the individual authorship, as the highest rate was only $28.9 \%$ in the years between 2010 to 2017. Findings of the study thus indicated that most of the researchers are submitted by the individual authors, as a gradual development is observed in individual authorship.

Table 3. Publications with Respect to Authorship.

\begin{tabular}{ccccccc}
\hline Authorship style & \multicolumn{7}{c}{ Periods } \\
\cline { 2 - 7 } & $\mathbf{1 9 6 5 -}$ & $\mathbf{1 9 7 0}$ & $\mathbf{1 9 8 0}-$ & $\mathbf{1 9 9 0}-$ & $\mathbf{2 0 0 0 -}$ & $\mathbf{2 0 1 0}-$ \\
& $\mathbf{1 9 6 9}$ & $\mathbf{1 9 7 9}$ & $\mathbf{1 9 8 9}$ & $\mathbf{1 9 9 9}$ & $\mathbf{2 0 0 9}$ & $\mathbf{2 0 1 7}$ \\
\hline Co-authorship & $0 \%$ & $5.7 \%$ & $9.8 \%$ & $17.4 \%$ & $11.7 \%$ & $28.9 \%$ \\
Individual Author & $100 \%$ & $94.3 \%$ & $90.2 \%$ & $82.6 \%$ & $88.3 \%$ & $71.1 \%$ \\
\hline
\end{tabular}

According to Table 4, the types of researches published from year 1965 to 2017 were identified separately from highest published article type to lowest publications. In the time period of 1965- 1969 subjects that have more frequency in publications were: Biographies $(n=14)$, cataloging $(n-10)$, bibliographies $(n=9)$, public libraries $(n=8)$, books reviews $(n=8)$ and classification $(n=8)$.

In the second period i.e., between 1970-1979, subjects that have shown more publications on topics were: Biographies $(n=24)$, Book Reviews $(n=20)$, Bibliographies ( $n=17)$, library associations $(n=14)$, and public libraries $(n=12)$ etc. Similar trend of topics has been observed during the third period of the classification i.e., between 1980-1989, where major published work was in the form of book reviews $(n=21)$, followed by library automation $(n=17)$ and book reviews $(n=15)$.

Table 4. Topic Areas and Number of Researches Published

\begin{tabular}{ccccccc}
\hline & \multicolumn{7}{c}{ Periods } \\
\cline { 2 - 7 } Area of Study & $\mathbf{1 9 6 5 -}$ & $\mathbf{1 9 7 0 -}$ & $\mathbf{1 9 8 0}$ & $\mathbf{1 9 9 0}$ & $\mathbf{2 0 0 0}$ & $\mathbf{2 0 1 0}$ \\
& $\mathbf{1 9 6 9}$ & $\mathbf{1 9 7 9}$ & $\mathbf{1 9 8 9}$ & $\mathbf{1 9 9 9}$ & $\mathbf{2 0 0 9}$ & $\mathbf{2 0 1 7}$ \\
\cline { 2 - 7 } Abstracting & $\mathrm{N}$ & $\mathrm{N}$ & $\mathrm{N}$ & $\mathrm{N}$ & $\mathrm{N}$ & $\mathrm{N}$ \\
Acquisition & 1 & - & 1 & 1 & 1 & - \\
Archiving & - & 2 & 2 & - & - & 1 \\
Biographies & - & - & - & 2 & 8 & 11 \\
Bibliographies & 9 & 24 & 1 & 6 & - & 2 \\
Bibliographic cen- & - & 17 & 7 & 1 & - & - \\
ters & & - & 1 & - & - & - \\
Books reviews & 8 & 20 & 21 & 9 & 10 & - \\
Book maintenance & - & 4 & 1 & - & - & - \\
Book fairs & - & 4 & - & 1 & - & - \\
Cataloging & 10 & 12 & 7 & 11 & 2 & 1 \\
Classification & 8 & 6 & 1 & 4 & 2 & 1 \\
Catalogues & 2 & - & 3 & - & - & 1 \\
Career ethics & - & - & - & 1 & 2 & 2 \\
Children literature & 4 & 5 & 9 & 10 & 2 & - \\
Children library & 2 & - & 5 & 6 & 1 & 3 \\
Circulation & 1 & 1 & 3 & - & - & - \\
Culture & 1 & - & 1 & 1 & 6 & 2 \\
Databases & - & - & 3 & 8 & 2 & 2 \\
\hline
\end{tabular}




\begin{tabular}{|c|c|c|c|c|c|c|}
\hline Deposit Law & - & 3 & 2 & - & - & - \\
\hline Documentation & 2 & 1 & 3 & 2 & 1 & - \\
\hline Digital Library & - & - & - & - & 2 & 7 \\
\hline $\begin{array}{l}\text { Electronic publish- } \\
\text { ing/Management }\end{array}$ & - & - & 2 & - & 4 & 6 \\
\hline Encyclopedia & 2 & 4 & - & - & - & - \\
\hline Globalization & - & - & - & 1 & 1 & 1 \\
\hline Hospital library & - & - & - & 1 & - & 1 \\
\hline Indexing & - & - & - & 1 & - & - \\
\hline $\begin{array}{l}\text { Intellectual property } \\
\text { right }\end{array}$ & - & - & 6 & 3 & 1 & - \\
\hline Information centers & - & - & & 2 & 1 & - \\
\hline $\begin{array}{l}\text { Information man- } \\
\text { agement/Infor- } \\
\text { mation }\end{array}$ & - & - & 2 & & 2 & 9 \\
\hline $\begin{array}{l}\text { Information econ- } \\
\text { omy }\end{array}$ & - & - & - & - & 3 & - \\
\hline $\begin{array}{l}\text { Information technol- } \\
\text { ogy }\end{array}$ & - & - & 4 & 3 & 5 & 7 \\
\hline $\begin{array}{l}\text { Information re- } \\
\text { sources }\end{array}$ & - & - & 1 & 1 & 1 & 7 \\
\hline Information Security & - & - & - & - & - & 5 \\
\hline Information services & & - & - & - & 4 & 5 \\
\hline Information Society & - & - & - & - & - & 9 \\
\hline Information systems & - & 1 & 2 & 16 & 3 & 3 \\
\hline $\begin{array}{l}\text { Information Storage } \\
\text { and Retrieval }\end{array}$ & 1 & - & 1 & 2 & - & - \\
\hline $\begin{array}{l}\text { Intellectual produc- } \\
\text { tion }\end{array}$ & - & - & 4 & 2 & 2 & - \\
\hline Internet & - & - & - & 6 & 12 & 8 \\
\hline ISBN & - & 1 & 1 & 1 & - & - \\
\hline Knowledge & - & - & - & 1 & 1 & 2 \\
\hline $\begin{array}{l}\text { Knowledge Manage- } \\
\text { ment }\end{array}$ & - & - & - & - & - & 11 \\
\hline Knowledge Society & - & - & - & - & - & 4 \\
\hline Libraries & 6 & 5 & 6 & 2 & 3 & - \\
\hline Librarians & 1 & - & 6 & - & 1 & 1 \\
\hline Library automation & 2 & 4 & 17 & 6 & 6 & 2 \\
\hline Library legislations & - & 2 & - & 1 & 2 & - \\
\hline Library services & 2 & 2 & 9 & 1 & - & - \\
\hline Library associations & 5 & 14 & 15 & 17 & 4 & 1 \\
\hline Library cooperation & 2 & 5 & 5 & 10 & 2 & - \\
\hline Library terminology & - & 1 & - & 1 & 1 & - \\
\hline $\begin{array}{l}\text { Library manage- } \\
\text { ment }\end{array}$ & & 2 & 3 & 7 & 5 & 17 \\
\hline Periodicals & 2 & 3 & 7 & 4 & - & 1 \\
\hline Printing & - & 1 & - & 1 & - & - \\
\hline Public libraries & 8 & 12 & 6 & 6 & 4 & 2 \\
\hline School libraries & 1 & 7 & 8 & 7 & 7 & 12 \\
\hline $\begin{array}{l}\text { Scientific communi- } \\
\text { cation }\end{array}$ & - & - & 2 & 4 & 1 & - \\
\hline
\end{tabular}




\begin{tabular}{lllllll}
\hline Scientific research & - & - & 3 & 2 & 2 & 1 \\
Selective dissemina- & - & 1 & - & - & - & - \\
tion of information & & & & & & \\
Specialized libraries & 6 & 12 & 7 & 3 & - & 1 \\
$\quad$ Standards & - & - & 1 & - & - & - \\
$\quad$ Maps & - & - & 1 & - & - & - \\
Manuscripts & - & 4 & 4 & 3 & 2 & 1 \\
$\quad$ Media & 1 & - & - & - & - & - \\
Mobile libraries & 1 & - & 1 & 3 & 2 & - \\
National libraries & 5 & - & 1 & 3 & 2 & - \\
Networks & - & - & 1 & 1 & - & - \\
Quality Manage- & - & - & - & - & 2 & - \\
$\quad$ ment & & & & & & \\
Audio-visual re- & 1 & 2 & 8 & 1 & - & - \\
sources & & & & & & \\
University library & 3 & 7 & 4 & 4 & 5 & 12 \\
Publishing & 1 & 2 & 9 & - & 1 & - \\
Teaching library sci- & - & 1 & 12 & 9 & 7 & 6 \\
ence & & - & & & & \\
Thesaurus & - & - & 2 & 2 & 2 & - \\
Training (librarians) & 1 & 10 & 9 & 2 & 2 & 2 \\
Training (users) & - & & 5 & 1 & - & - \\
Reading & 1 & 9 & 2 & 3 & - & - \\
References & 3 & 7 & 3 & 1 & - & - \\
Reference citations & - & - & - & 2 & - & - \\
Women librarians & - & 1 & - & 1 & - & - \\
\hline
\end{tabular}

In the fourth period of publication i.e., between 1990-1999, subjects that were published with high frequency includes: library associations $(n=17)$, information systems $(n=16)$, Cataloging $(n=11)$, and children literature $(n=10)$. However, the lowest published subjects in 90s were Indexing, Archiving, career ethics, Globalization, Archiving Knowledge Book fairs and few more with $(n=1)$. In the fifth period of publication i.e. between 2000-2009, subjects that were frequently published were: Internet $(n=12)$, Book Review $(\mathrm{n}=10)$ and Archiving $(\mathrm{n}=8)$, whereas, lowest published subjects included: Knowledge, Electronic archiving, Abstracting, electronic government, virtual library, knowledge management, Publishing and few more with numbers of $(n=1)$ publications.

In the final period of the study i.e. between 2010-2017, topics that were frequently published included: library management $(n=17)$, school library $(n=12)$, university library $(\mathrm{n}=12)$, Archiving and knowledge management $(\mathrm{n}=11)$, information management and information society $(n=9)$. Whereas, the lowest subject publication in the following years include: scientific research, electronic learning, Individual libraries, Specialized libraries, Periodicals, library associations, hospital library etc. with frequency of $(n=1)$ publications.

The above table clearly indicates that some topics were highly focused by the authors and were written throughout the given periods i.e. between 1965 to 2017. Area of studies such as; Biographies, cataloging, bibliographies, public libraries, books reviews, Libraries, and library associations were the most common. However, some attempts have been carried out to explore new topics which include, databases, information systems, Internet, Archiving, library automation, knowledge management, information management, information society, and digital library. The analysis further outlined that certain types of papers such as; acquisition, virtual libraries, MARC composition, thesaurus etc. failed to attract widespread attention of the researchers. 
Findings further indicated that the topics that were written more intensively than others in the 1960s and 1970s were Biographies, in 1980s focus was majorly on book reviews. However, in 1990s library associations were the most common, while in the decade of 2000 focused shifted from Internet to library management. The results of this study showed that, the Jordanian Journal of Libraries and Information is published on all topics and is not specialized in any particular area within the libraries.

Finally, the bibliometric assessment of the study revealed that Jordanian Journals of Libraries and Information deals with the variety of study types, where majority of the studies were published by male authors, along with those consisting of the single authorship. Also, in comparison to other Journals, the Jordanian Journal of Libraries and Information is not specialized to any particular type of publications and thus welcomes diverse knowledge and information.

\subsection{Study Limitations}

The spatial limit in this study was that the researches published in the Jordanian Journal of Libraries and Information published by the Jordanian Library and Information Association was considered in the present study. According to the subject limit, only the bibliometric study approach was used. Another limitation includes the time limit, where studies that were published only during the period of 1965-2017 were included.

\section{Conclusions}

This study concludes that by converting the libraries into electronic medium and channels, the researchers are encouraged to produce more articles frequently. Besides, conducting bibliographical studies on the online database of the researches such as those published in the Jordanian Journal of Libraries and Information are effective in providing a useful estimation of the existing developments taking place in the field of education and research. Such studies are further needed to be conducted to provide insights regarding the topics that requires attention for more in-depth researches. Considering the results of this study, it is recommended to issue licenses for publishing and printing the articles in various journals to encourage authors for producing more productive information which may serve as an economic gain in wider perspective. Finally, provision of free access to most of the libraries in Jordan is suggested to increase the interest of audience and that of authors towards studying the topics that attract high readership.

Funding: This research received no external funding.

Acknowledgements: This study is not supported through any source.

Conflict of interest: The authors declare no conflict of interest.

\section{References}

[1]. Resnik, Julia. "The production of educational knowledge in the global era,". Sense Publication, 2008. https://doi.org/10.1163/9789087905613

[2]. Abu, Al Tawalbeh S.D, Ahmed M.H. “Jordanian Intellectual Production from 2002-2011: a bibliometric analysis,". J. Inf. Knowl. Manag 2016, Volume. 6, 11-16

[3]. Anwar, Muhammad. "Journal of information technology education: A Bibliometric study from 2002 to 2007," Pak. j. libr. inf. sci. Journal 2019, Volume. 50.

[4]. Thanuskodi. "Journal of Social Sciences: a bibliometric study," J. Soc. Sci 2010, Volume 24, 77-80. https://doi.org/10.1080/09718923.2010.11892847

[5]. Welsh, Teresa S. "Qualitative and quantitative methods in libraries journal special issue: Bibliometrics and scientometrics," Qualitative and Quantitative Methods in Libraries: 1-3, 2017.

[6]. Krauskopf, Erwin. “A bibiliometric analysis of the Journal of Infection and Public Health: 2008-2016,". J Infect Public Health 2018, Volume. 11, 224-229.https://doi.org/10.1016/j.jiph.2017.12.011 
[7]. Kalantari, Ali, Amirrudin Kamsin, Halim Shukri Kamaruddin, Nader Ale Ebrahim, Abdullah Gani, Ali Ebrahimi, Shahaboddin Shamshirband. "A bibliometric approach to tracking big data research trends,". J Big Data 2017, Volume 4, 30. https://doi.org/10.1186/s40537-017-0088-1

[8]. ODLIS. (n.d.). “Online Dictionary for Library and Information Science,”. Available at: http://library.wcsu.edu/people/reitz/ODLIS/odlis\%20new.html

[9]. Hodonu-Wusu, James Oluwaseyi, Gift Nneka Lazarus. "Major Trends in Lis Research: A Bibliometric Analysis,". Libr. philos. pract. 2018. https://doi.org/10.1109/scored.2018.8710817

[10]. Lewis, Danica M, Kristine M. Alpi. “Bibliometric network analysis and visualization for serials librarians: An introduction to Sci2,". Ser. Rev. 2017. Volume. 43, 239-245. https://doi.org/10.1080/00987913.2017.1368057

[11]. Ur Rehman, Sajjad, Abdus Sattar Chaudhry. "KM education in LIS programs," Educ. Inf. Volume 2005, $23,245-258$. https://doi.org/10.3233/efi-2005-23403

[12]. Sulieman, Raid Jameel. “Understanding School Library Education and Library User Education in Jordan," 2016. https://doi.org/10.30958/ajms.2-3-4

[13]. Bakri, Aryati, Peter Willett. "The Malaysian journal of library and information science 2001-2006: A bibliometric study,". Malays. J. Libr. Inf. Sci. 2017. Volume 13, 103-116.

[14]. Tiew, Wai Sin, Abrizah Abdullah, Kiran Kaur. “Malaysian Journal of Library and Information Science1996-2000: A Bibliometric Study,". Malays. J. Libr. Inf. Sci. 2001. Volume 6, pp. 43-56.

[15]. Gore, Sally A., Judith M. Nordberg, Lisa A. Palmer, Mary E. Piorun. “Trends in health sciences library and information science research: an analysis of research publications in the Bulletin of the Medical Library Association and Journal of the Medical Library Association from 1991 to 2007,". J Med Libr Assoc 2009, Volume 97, 203. https://doi.org/10.3163/15365050.97.3.009

[16]. Huang, Mu-Hsuan, Yu-Wei Chang. "A study of interdisciplinarity in information science: using direct citation and coauthorship analysis." J. Inf. Sci. Volume 2011, 37, pp. 369-378. 10.1177/0165551511407141 